\title{
Desain dan Analisis Flat Slab dengan Software Matlab
}

\author{
Samsul A Rahman Sidik Hasibuan ${ }^{1}$, Dwi Kurniati ${ }^{2}$, Mega Puspita Sari ${ }^{3}$ \\ ${ }^{1,3}$ Universitas Medan Area, ${ }^{2}$ Universitas Teknologi Yogyakarta \\ DOI: http://dx.doi.org/10.26623/teknika.v14i2.kodeartikel
}

\section{Info Artikel}

Sejarah Artikel:

Disubmit 11-06-2020

Publish 30-12-2020

\section{Keywords:}

Drop panel; Flat slab; Punching shear; Matlab; SNI 2847:2019

\begin{abstract}
Abstrak
Flat slab adalah pelat beton bertulang yang didukung oleh kolom ditambah drop panel atau mungkin kolom ditambah kepala kolom atau tanpa kepala kolom dan drop panel. Metode desain dan analisis flat slab yang digunakan adalah metode desain langsung dengan ditentukan berdasarkan ketebalan minimum pelat yang ditinjau dari mutu baja yang digunakan pada analisis ini. Distribusi momen pada analisis dengan metode desain langsung menghasilkan momen total yang kemudian akan didistribusi ke masing-masing panel untuk lajur kolom dan lajur tengah. Kegagalan geser (punching shear) terjadi pada area penampang kritis di sekitar kepala kolom dan drop panel sehingga kekuatan geser akan dihitung berdasarkan nilai kekuatan geser yang terjadi dan akan di kontrol dengan kekuatan geser dari mutu beton yang digunakan. Dalam tulisan ini desain dan analisis dilakukan secara numerik berdasarkan Standar Nasional Indonesia 2847, 2019 dengan menggunakan software Matlab. Hasil analisis menunjukan bahwa ketebalan minimum flat slab yang diatur oleh Standar Nasional Indonesia (SNI) 2847, 2019 mampu menahan beban hidup rencana sebesar $7 \mathrm{kN} / \mathrm{m} 2$, tetapi pelat perlu diperkuat oleh tulangan baja dengan total luasan sebesar $1.882 \mathrm{~mm} 2$. Sehingga panel internal yang didesain aman dari kegagalan punching shear.
\end{abstract}

\section{Abstract}

Flat slab is a reinforced concrete slab that is supported by columns with added drop panels or columns with added column heads or without column heads and drop panels. The flat slab design and analysis method to be used is the direct design method where the method is to determine the minimum thickness of the plate under review based on the quality of the steel that will be used in this analysis. Moment distribution on analysis by direct design method produces total moment which will then be distributed to each panel for column strip and middle strip. Punching shear occurs in the critical crosssectional area around the column heads and drop panels so the shear strength will be calculated based on the value of the shear strength that occurs and will be controlled by the shear strength of the quality of the concrete used. In this papers design and analysis will be done numerically based on SNI 2847:2019 using Matlab software. Furthermore, the results of the analysis that have been obtained from the Matlab software shows that the designed internal panel is safe from punching shear failure.

Alamat Korespondensi:

p-ISSN $1410-4202$

E-mail: Samsulhasibuan@gmail.com 


\section{PENDAHULUAN}

Meningkatnya jumlah penggunaan beton dari waktu ke waktu yang menyebabkan jumlah sumber daya yang tersedia menurun, beton selama ini merupakan material bangunan yang harganya realtif mahal (Musthofa, 2021). Kontruksi beton harus dirancang agar memenuhi efektifitas kenyamanan dan pemanfaatan ruangan agar terpenuhinya kekuatan yang maksimal dan efisien (Sujiat, 2020). Pelat diklasifikasikan dalam pelat satu arah dan pelat dua arah. Pelat yang berdefleksi secara dominan dalam satu arah disebut pelat satu arah. Pelat yang dipikul oleh kolom yang disusun berbaris sehingga pelat dapat berdefleksi dalam dua arah disebut pelat dua arah (McCormac, 2000). Tahun 1906 seorang ahli dari luar negeri yang bernama Turner untuk pertama kalinya mengembangkan suatu tipe konstruksi yang tidak menggunakan salah satu komponen utama yaitu balok. Tipe konstuksi tanpa menggunakan balok lebih dikenal dengan sebutan flat slab (Gasparini, 2002). Flat slab adalah pelat beton bertulang yang didukung oleh kolom ditambah drop panel atau mungkin kolom ditambah kepala kolom atau tanpa kepala kolom (Maryam, 2019). Flat slab termasuk pelat dua arah non prategang, flat slab adalah pelat beton bertulang yang mentransfer beban langsung ke kolom tanpa adanya balok sepanjang garis kolom dalam, namun balok tepi luar boleh jadi ada atau tidak disesuaikan dengan kebutuhan. Flat slab mempunyai kekuatan geser yang cukup, karena terdapat drop panel yang merupakan penebalan pelat di kepala kolom untuk mengurangi jumlah tulangan negatif di daerah pendukung (Nirkhe, 2015). Flat slab sangat cocok untuk beban berat dan bentang panjang. Sistem pelat diizinkan untuk didesain dengan prosedur yang memenuhi kondisi kesetimbangan dan kompatibilitas geometrik, yang memenuhi kekuatan desain di setiap penampang paling sedikit sama dengan kekuatan perlu, dan semua persyaratan kemampuan layan terpenuhi (SNI 2847, 2019).

Menurut Vargeshe (2005) kelebihan dari struktur flat slab yaitu mampu mereduksi tinggi bangunan, menghemat kontruksi material, kemudahan dalam akses dan akomodasi penyaluran mekanikal dan elektrikal. Kelemahan struktur flat slab adalah kurangnya ketahanan terhadap beban lateral, seperti yang disebabkan oleh angin kencang dan gempa bumi, sehingga dinding geser harus selalu disediakan jika digunakan dalam kontruksi tingkat tinggi. Flat slab memiliki berbagai macam tipe yang dapat dilihat pada Gambar 1.

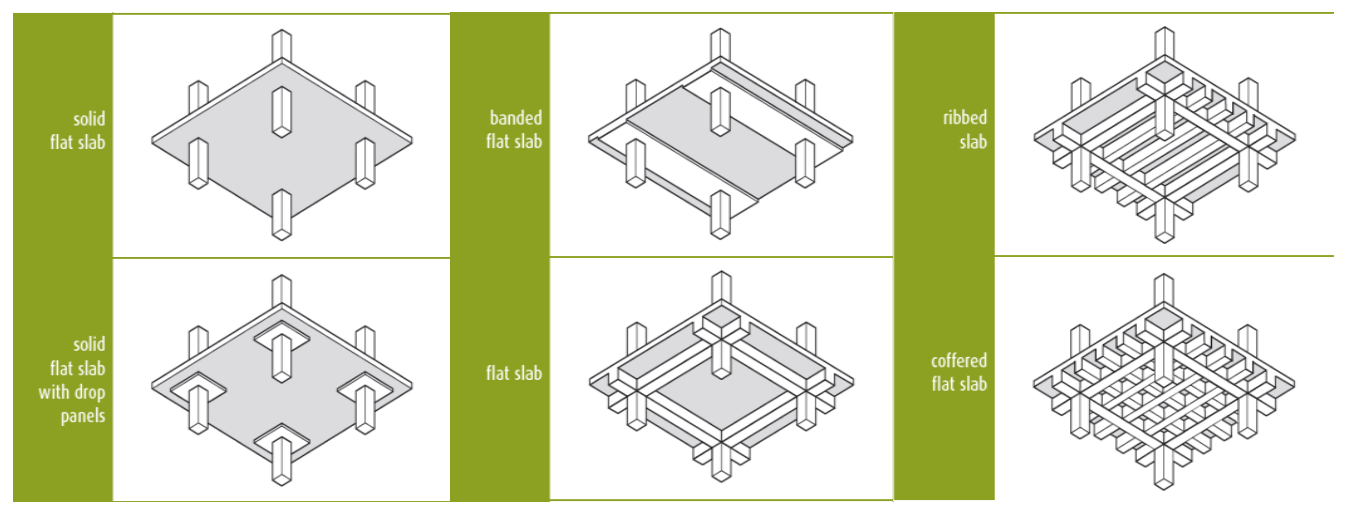

Gambar 1. Tipe Flat Slab

Sumber: Freyssinet, 2014

Kegagalan geser pada struktur flat slab terjadi pada area disekitar penampang kritis yang dapat dilihat pada Gambar 2. Menurut SNI 2847 (2019) untuk pelat nonprategang tanpa balok interior yang membentang di antara tumpuan pada semua sisinya yang memiliki rasio bentang panjang terhadap bentang pendek maksimum 2 , ketebalan pelat keseluruhan tidak boleh kurang dari batasan pada Tabel 1. ln adalah jarak bersih ke arah memanjang, diukur dari muka ke muka tumpuan $(\mathrm{mm})$. Untuk fy dengan nilai diantara yang diberikan dalam Tabel, ketebalan minimum harus dihitung dengan interpolasi linear. 


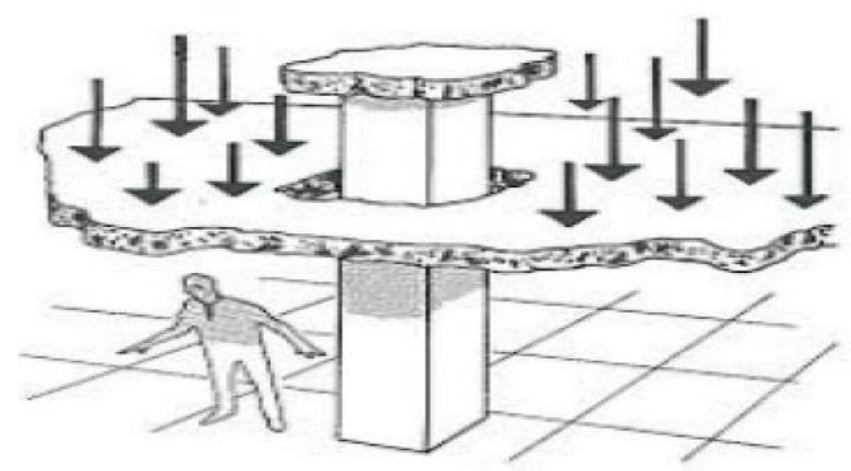

Gambar 2. Punching Shear

Sumber: Ali, 2015

Tabel 1. Ketebalan Minimum Pelat Dua Arah Nonprategang Tanpa Balok Interior

\begin{tabular}{|c|c|c|c|c|c|c|}
\hline \multirow{3}{*}{$\begin{array}{l}F \mathrm{y}, \\
(\mathrm{Mpa})\end{array}$} & \multicolumn{3}{|c|}{ Tanpa penebalan } & \multicolumn{3}{|c|}{ Dengan penebalan } \\
\hline & \multicolumn{2}{|c|}{ Panel eksterior } & \multirow[t]{2}{*}{$\begin{array}{l}\text { Panel } \\
\text { interior }\end{array}$} & \multicolumn{2}{|c|}{ Panel eksterior } & $\begin{array}{l}\text { Panel } \\
\text { interior }\end{array}$ \\
\hline & $\begin{array}{c}\text { Tanpa balok } \\
\text { tepi }\end{array}$ & $\begin{array}{c}\text { Dengan balok } \\
\text { tepi }\end{array}$ & & $\begin{array}{c}\text { Tanpa } \\
\text { balok tepi }\end{array}$ & $\begin{array}{c}\text { Dengan } \\
\text { balok tepi }\end{array}$ & \\
\hline 280 & $\ln / 33$ & $\ln / 36$ & $\ln / 36$ & $\ln / 36$ & $\ln / 40$ & $\ln / 40$ \\
\hline 420 & $\ln / 30$ & $\ln / 33$ & $\ln / 33$ & $\ln / 33$ & $\ln / 36$ & $\ln / 36$ \\
\hline 520 & $\ln / 28$ & $\ln / 31$ & $\ln / 31$ & $\ln / 31$ & $\ln / 34$ & $\ln / 34$ \\
\hline
\end{tabular}

Menurut SNI 2847 (2019) untuk drop panel pada pelat nonprategang yang digunakan untuk mengurangi ketebalan perlu minimum sesuai Tabel 1 harus memenuhi 1) dan 2):

1. Drop panel harus menjorok di bawah pelat paling sedikit seperempat tebal pelat bersebelahan;

2. Drop panel harus diteruskan di setiap arah dari garis pusat tumpuan dengan sebuah kepala kolom, yang digunakan untuk memperbesar penampang kritis geser pada joint pelat-kolom, harus menjorok di bawah pelat dan diteruskan secara horizontal dari muka kolom sejarak sekurang-kurangnya sama dengan ketebalan kepala kolom.

Untuk kepala kolom, ketebalan kepala kolom untuk pelat dengan perubahan ketebalan, penting untuk dilakukan pengecekan terhadap kekuatan jarak tidak kurang dari seperenam panjang bentang yang diukur dari pusat ke pusat tumpuan dalam arah tersebut. Jika sebuah elemen tumpuan tidak memiliki penampang persegi panjang atau jika salah satu sisi persegi tidak sejajar dengan bentang, harus diperlakukan sebagai tumpuan persegi dengan luas yang sama seperti pada Gambar 3. 

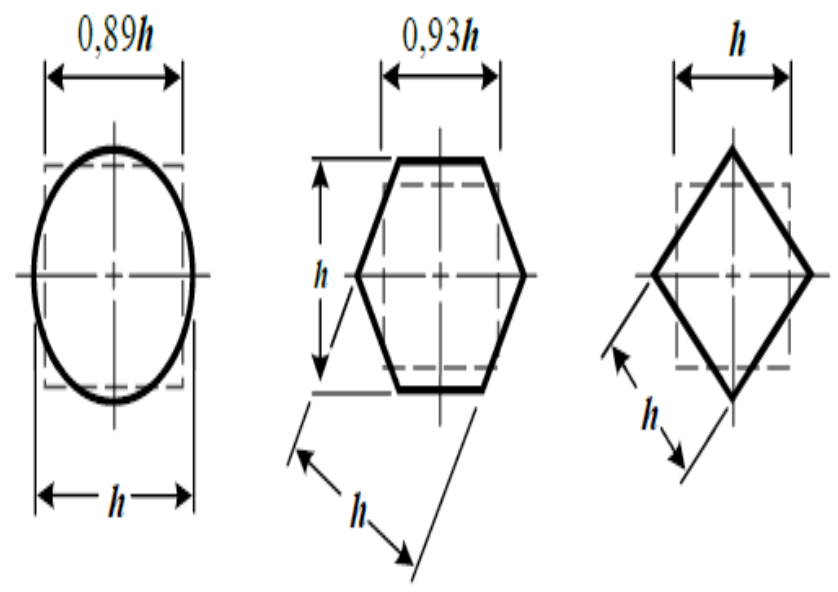

Gambar 3. Penampang Bujursangkar Ekuivalen Untuk Komponen Struktur Tumpuan Sumber: SNI 2847, 2019

Menurut Nichols (1914) dengan asumsi penyederhanaan bahwa reaksi terkonsentrasi sepanjang muka tumpuan yang tegak lurus terhadap bentang yang ditinjau. Secara umum perlu dihitung momen statis untuk dua panel yang bersebelahan masing-masing setengah bentang mencakup lajur kolom dengan lajur tengah kolom sepanjang sisinya. Jumlah absolut momen terfaktor positif dan negatif rata-rata $\mathrm{Mu}$ dalam setiap arah tidak boleh kurang dari Persamaan 1.

$$
\text { Mo }=\frac{q_{u} \ell_{2} \ell_{n}^{2}}{8}
$$

ln adalah jarak bentang bersih dalam arah momen-momen yang diperhitungkan, harus menerus dari muka ke muka kolom, kepala kolom, bracket, atau dinding, tidak boleh kurang dari $0,65 \ell 1$. Untuk mendistribusikan momen statis total terfaktor pada bentang interior, Mo harus didistribusikan sebesar $0,65 \mathrm{Mo}$ ke momen negatif dan $0,35 \mathrm{Mo}$ ke momen positif. Untuk mendistribusikan momen statis total terfaktor pada bentang ujung Mo harus didistribusikan seperti pada Tabel 2 dan Gambar 4.

Tabel 2. Koefisien Distribusi Untuk Bentang Ujung

\begin{tabular}{|c|c|c|c|c|c|}
\hline & \multirow{2}{*}{$\begin{array}{c}\text { Tepi } \\
\text { eksterior } \\
\text { tak } \\
\text { terkekang }\end{array}$} & \multirow{2}{*}{$\begin{array}{c}\text { Pelat dengan } \\
\text { balok antara } \\
\text { semua } \\
\text { tumpuan } \\
\end{array}$} & \multicolumn{2}{|c|}{$\begin{array}{l}\text { Pelat tanpa balok } \\
\text { antara tumpuan } \\
\text { interior }\end{array}$} & \multirow{2}{*}{$\begin{array}{c}\text { Tepi } \\
\text { eksterior } \\
\text { terkekang } \\
\text { penuh }\end{array}$} \\
\hline & & & $\begin{array}{c}\text { Tanpa } \\
\text { balok } \\
\text { tepi }\end{array}$ & $\begin{array}{c}\text { Dengan } \\
\text { balok } \\
\text { tepi }\end{array}$ & \\
\hline $\begin{array}{l}\text { Negatif } \\
\text { interior }\end{array}$ & 0,75 & 0,70 & 0,70 & 0,70 & 0,65 \\
\hline Positif & 0,63 & 0,57 & 0,52 & 0,50 & 0,35 \\
\hline $\begin{array}{l}\text { Negatif } \\
\text { eksterior }\end{array}$ & 0 & 0,16 & 0,26 & 0,30 & 0,65 \\
\hline
\end{tabular}

Sumber: SNI 2847, 2019 


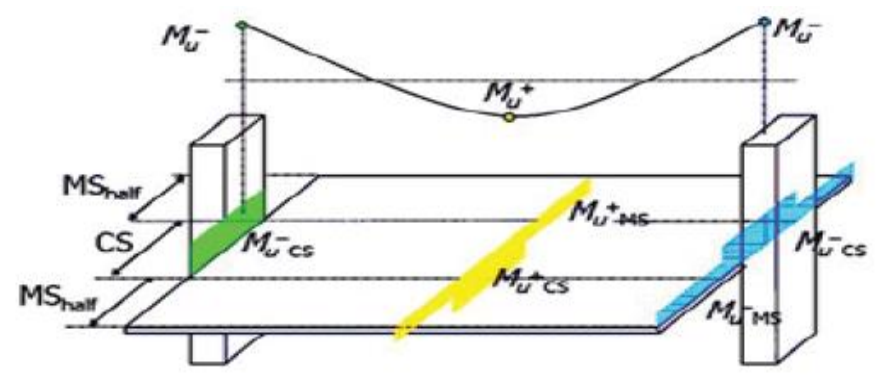

Gambar 4. Distribusi Momen Untuk Lajur Kolom Dan Lajur Tengah Sumber: Chavan dan Tande, 2016

Penampang kritis yang ideal ditempatkan dengan jarak $\mathrm{d} / 2$ dari keliling daerah yang menerima beban. Untuk komponen dengan ketebalan sama tanpa tulangan geser, diperbolehkan untuk meninjau geser hanya dari satu penampang. Penampang kritis geser dua arah pada pelat dengan tulangan geser pada kolom interior dapat dilihat pada Gambar 5.

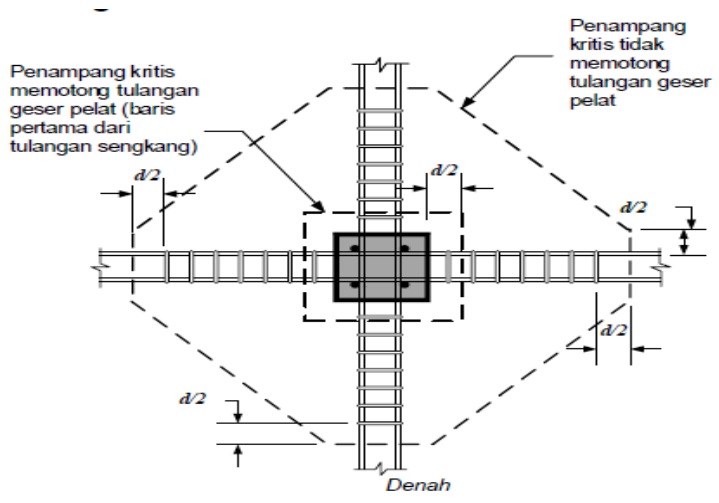

Gambar 5. Penampang Kritis Geser Dua Arah Pada Pelat Dengan

Tulangan Geser Pada Kolom Interior

Sumber: SNI 2847, 2019

\section{METODE}

Metode desain dan analisis yang digunakan adalah metode desain langsung dengan menentukan tebal minimum pelat yang ditinjau berdasarkan mutu baja yang digunakan pada analisis ini. Distribusi momen pada analisis dengan metode desain langsung menghasilkan momen total yang kemudian didistribusikan ke masingmasing panel untuk lajur kolom dan lajur tengah. Kegagalan geser (punching shear) terjadi pada area penampang kritis disekitar kepala kolom dan drop panel sehingga kekuatan geser akan dihitung berdasarkan nilai kekuatan geser yang terjadi dan akan di kontrol dengan kekuatan geser dari mutu beton yang digunakan, jika kekuatan geser yang terjadi lebih besar dari kekuatan geser beton maka dibutuhkan penguat geser pada struktur flat slab. Penelitian ini akan dianalisis secara numerik dengan menggunakan bahasa pemograman Matlab. Adapun objek yang akan dianalisis ditampilkan pada Gambar 6 sedangkan untuk data-data analisis adalah sebagai berikut:

1. Panel internal dengan ukuran $6 \times 5 \mathrm{~m}$;

2. Beban hidup rencana sebesar $7 \mathrm{kN} / \mathrm{m} 2$;

3. Mutu beton f'c $20 \mathrm{MPa}$;

4. Mutu baja fy $290 \mathrm{MPa}$;

5. Dimensi kolom bulat $0,45 \mathrm{~m}$;

6. Tinggi $3,5 \mathrm{~m}$. 


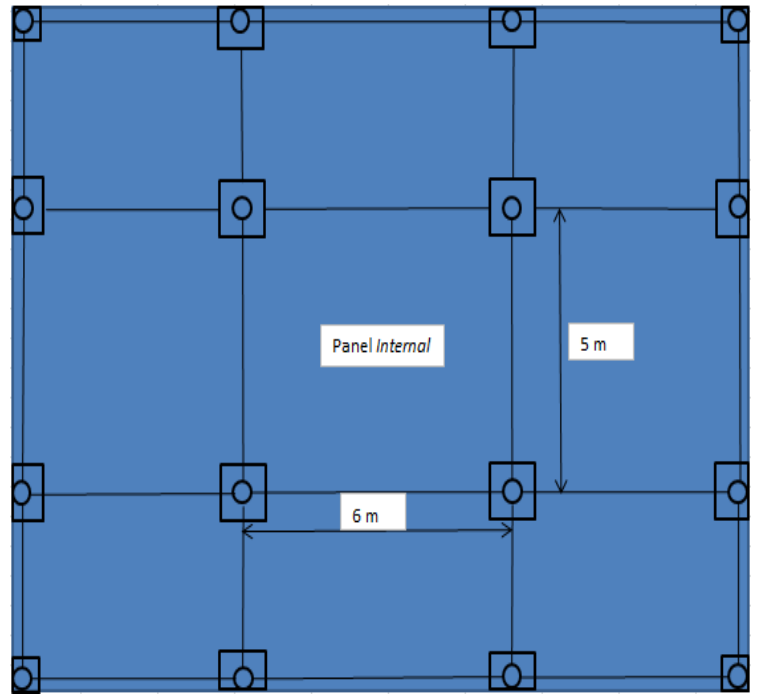

Gambar 6. Objek Penelitian

Sumber : Instrumen Penelitian, 2021

\section{HASIL DAN PEMBAHASAN}

\section{Hasil}

Hasil distribusi koefesien momen dapat dilihat pada Tabel 3 dan hasil rekapitulasi analisis dengan Matlab dapat dilihat pada Tabel 4.

Tabel 3. Hasil Distribusi Koefisien Momen

\begin{tabular}{ccc}
\hline Distribusi momen & Lajur Kolom & Lajur Tengah \\
& 0,65 & 0,35 \\
\hline Bending momen negatif & 0,139 & 0,046 \\
\hline Bending momen positif & 0,060 & 0,040 \\
\hline
\end{tabular}

Sumber : Hasil Penelitian, 2021

Tabel 4. Hasil Rekapitulasi Analisis dengan Matlab

\begin{tabular}{|c|c|c|}
\hline Tebal flat slab (mm) & & 151 \\
\hline Tebal drop panel (mm) & & 189 \\
\hline Ukuran drop panel (mm) & & $2000 \times 2000$ \\
\hline Ukuran kepala kolom (mm) & & 1000 \\
\hline \multirow{2}{*}{ Momen max negatif $(\mathrm{kNm})$} & lajur kolom & 55,98 \\
\hline & lajur tengah & 18,56 \\
\hline \multirow{2}{*}{ Momen max positif $(\mathrm{kNm})$} & lajur kolom & 24,11 \\
\hline & lajur tengah & 16,08 \\
\hline $\begin{array}{l}\text { Total area penulangan baja } \\
\qquad(\mathrm{mm} 2)\end{array}$ & & 1.882 \\
\hline Punching shear & & Aman \\
\hline
\end{tabular}

Sumber : Hasil Penelitian, 2021 


\section{Pembahasan}

a) Bending momen: Bending momen harus $65 \%$ atau bahkan $75 \%$ didistribusi ke momen negatif karena untuk memperkuat daerah disekitar lajur kolom yang rawan mengalami kegagalan punching shear.

b) Punching shear: nilai geser aktual hasil analisis sebesar $279,35 \mathrm{kN}$, sedangkan geser yang diizinkan oleh beton sebesar $602,32 \mathrm{kN}$, ini berarti bahwa hasil desain struktur flat slab aman dari punching shear.

\section{SIMPULAN}

Dari hasil dan pembahasan yang telah dipaparkan sebelumnya, maka ditarik kesimpulan bahwa ketebalan minimum flat slab yang diatur oleh SNI 2847, 2019 mampu menahan beban hidup rencana sebesar 7 $\mathrm{kN} / \mathrm{m}^{2}$, namun pelat perlu diperkuat oleh tulangan baja dengan total luasan sebesar $1.882 \mathrm{~mm}^{2}$. Momen negatif dan momen positif terbesar terjadi pada lajur kolom, tentu hal ini dapat menjadi perhatian. Overall, hasil desain dan analisis struktur flat slab khususnya panel internal aman dari kegagalan punching shear. Selanjutnya setelah diamati apabila desain dan analisis flat slab dengan menggunakan software Matlab selesai diprogramkan, maka untuk analisis selanjutnya dengan kasus flat slab namun dengan ukuran, mutu beton, mutu baja, diameter kolom dan juga beban hidup yang berbeda, maka software Matlab akan jauh lebih cepat dari software lainnya.

\section{DAFTAR PUSTAKA}

Chavan, G.R. Tande, S.N. (2016). Analysis and Design of Flat slab. International Journal of Latest Trends in Engineering and Technology. (IJLTET). Vol 7, issue 1.

Freyssinet., (2014). PT Concrete Slabs. Hongkong: Freyssinet Hong Kong Ltd.

Gasparini D. A., (2002) Contributions of C. A. P. Turner to Development of Reinforced Concrete Flat slabs 1905-1909, J. of Structural Engineering, 128(10):1243-52p.

Girish, N., Lingeshwaran, N., (2018). A Comparative Study of Flat slabs Using Different Shear Reinforcement Parameters, International Journal of Engineering \& Technology, 7 (2.20) (2018) 321-325.

Hasibuan, S., \& Kurniati, D. (2020) "Redesain Awana Condotel Menggunakan Metode Flat Slab Berdasarkan SNI 2847:2013," TEKNIK, 41(1), hal. 92-99. doi: 10.14710/teknik.v41n1.23742.

Imran, A. (2015). Advanced R.C.C Design, diakses 2015,https://www.slideshare.net/imranali108/design-of-flat-slab.

Mariyam., Jamle, S., (2019). A Technical Approach to Flat slab Multistorey Building under Wind Speed of $39 \mathrm{~m} / \mathrm{s}$, International Research Journal of Engineering and Technology (IRJET). Volume: 06 Issue: 05.

McCormac, J. (2000). Desain Beton Bertulang Jilid 1 Edisi Keempat. Jakarta: Erlangga.

Musthofa \& Amanda P., (2021) Subtitusi Agregat Beton Menggunakan Tanah Urug Limestone Dari Kecamatan Rengel Kabupaten Tuban, Teknika, Vol 16 : No 1.

Nirkhe, S.P., Kakade, D.N., Dahake, A.G., (2016) Design of Flat slab with Matlab, International Journal of Engineering Research, Volume No.5 Issue: Special 3, pp: 537-540.

Nirkhe, S.P., Kakade, D.N., (2015) Analysis of Flat slab by MATLAB Coding, International Journal of Construction Engineering and Planning, Vol. 1: Issue 2.

Patil, S.S., Sigi Rupali A., (2014). Flat slab Construction in India, International Journal of Engineering and Innovative Technology (IJEIT), Volume 3, Issue 10.

Pratap R., (2010). Getting Started with MATLAB, A Quick Introduction for Scientists and Engineers, 1st Edn, Oxford University Press.

SNI 2847, (2019). Persyaratan beton struktural untuk bangunan gedung dan penjelasan, BSN, Jakarta.

Sujiat S \& Zainul I, (2020). Analisa Stuktur Beton Bertulang Bangunan Gedung Pusat Layanan Haji dan Umroh, Teknika, Vol 15 : No 1.

Vargeshe, (2005). Advanced Reinforced Concrete Design, Prentice-hall of India, New Delhi. 
